\title{
Acetabular components in total hip arthroplasty: is there evidence that cementless fixation is better?
}

\author{
Nader Toossi \\ Rothman Institute of Orthopedics, Thomas Jefferson University \\ Bahar Adeli \\ Rothman Institute of Orthopedics, Thomas Jefferson University \\ Andrew J Timperley \\ Exeter Hip Unit, Princess Elizabeth Orthopaedic Centre, Royal Devon and Exeter Hospital \\ Fares $S$ Haddad \\ LAT (ST3) Trauma and Orthopaedics, University College London Hospital \\ Mitchell Maltenfort \\ Rothman Institute of Orthopedics, Thomas Jefferson University \\ Follow this and additional works at: https://jdc.jefferson.edu/rothman_institute \\ Part of the Orthopedics Commons

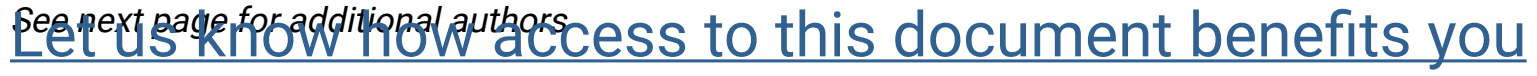

\section{Recommended Citation}

Toossi, Nader; Adeli, Bahar; Timperley, Andrew J; Haddad, Fares S; Maltenfort, Mitchell; and Parvizi, Javad, "Acetabular components in total hip arthroplasty: is there evidence that cementless fixation is better?" (2013). Rothman Institute Faculty Papers. Paper 26.

https://jdc.jefferson.edu/rothman_institute/26

This Article is brought to you for free and open access by the Jefferson Digital Commons. The Jefferson Digital Commons is a service of Thomas Jefferson University's Center for Teaching and Learning (CTL). The Commons is a showcase for Jefferson books and journals, peer-reviewed scholarly publications, unique historical collections from the University archives, and teaching tools. The Jefferson Digital Commons allows researchers and interested readers anywhere in the world to learn about and keep up to date with Jefferson scholarship. This article has been accepted for inclusion in Rothman Institute Faculty Papers by an authorized administrator of the Jefferson Digital Commons. For more information, please contact: JeffersonDigitalCommons@jefferson.edu. 


\section{Authors}

Nader Toossi, Bahar Adeli, Andrew J Timperley, Fares S Haddad, Mitchell Maltenfort, and Javad Parvizi 


\title{
Acetabular Components in Total Hip Arthroplasty: Is There Evidence That Cementless Fixation Is Better?
}

\author{
Nader Toossi, MD, Bahar Adeli, BA, Andrew J. Timperley, DPhil, FRCS, Fares S. Haddad, FRCS, \\ Mitchell Maltenfort, PhD, and Javad Parvizi, MD, FRCS \\ Investigation performed at the Rothman Institute of Orthopedics at Thomas Jefferson University Hospital, Philadelphia, Pennsylvania
}

\begin{abstract}
Background: The use of cementless acetabular components in total hip arthroplasty has gained popularity over the past decade. Most total hip arthroplasties being performed in North America currently use cementless acetabular components. The objective of this systematic review and meta-analysis was to compare the survivorship and revision rate of cemented and cementless acetabular components utilized in total hip arthroplasty.
\end{abstract}

Methods: A primary literature search in PubMed identified 3488 articles, of which 3407 did not meet the inclusion criteria and were excluded. Only English-language articles on either the survivorship or revision rate of primary total hip arthroplasty at a minimum of ten years of follow-up were included. The present study analyzed forty-five articles reporting the long-term outcome of cementless acetabular components, twenty-nine reporting the outcome of cemented acetabular components, and seven comparing cemented and cementless acetabular components. Metaanalysis (with a random-effects model) was performed on the data from the seven comparative studies, and study-level logistic regression analysis (with a quasibinomial model) was performed on the pooled data on the eighty-one included articles to determine a consensus. The studies were weighted according to the number of total hip arthroplasties performed.

Results: The meta-analysis did not reveal any effect of the type of acetabular component fixation on either survivorship or revision rate. The regression analysis revealed the estimated odds ratio for survivorship of a cemented acetabular component to be 1.60 ( $95 \%$ confidence interval, 1.32 to $2.40 ; p=0.002$ ) when adjustments for factors including age, sex, and mean duration of follow-up were made.

Conclusions: The preference for cementless acetabular components on the basis of improved survivorship is not supported by the published evidence. Although concerns regarding aseptic loosening of cemented acetabular components may have led North American surgeons toward the nearly exclusive use of cementless acetabular components, the available literature suggests that the fixation of cemented acetabular components is more reliable than that of cementless components beyond the first postoperative decade.

$\mathrm{U}$ ndoubtedly, the success of total hip arthroplasty and its worldwide acceptance are due to the durable cemented low-friction arthroplasty devised and popularized by Sir John Charnley ${ }^{1}$. Although initial acetabular components were cemented, cementless acetabular components have gained popularity over the years and have become the primary components of choice in North America. This is despite the availability of ample literature supporting the use of cemented acetabular components $\mathrm{s}^{2-6}$ and suggesting a less optimal survivorship for cementless components $\mathrm{s}^{7-14}$. However, there is a lack of long-term studies on the improved cementless implants that may have the potential for better survivorship and durability.

Cementless modular acetabular prostheses were introduced in the 1980s as a reaction to the perceived poor results of

Disclosure: None of the authors received payments or services, either directly or indirectly (i.e., via his or her institution), from a third party in support of any aspect of this work. One or more of the authors, or his or her institution, has had a financial relationship, in the thirty-six months prior to submission of this work, with an entity in the biomedical arena that could be perceived to influence or have the potential to influence what is written in this work. No author has had any other relationships, or has engaged in any other activities, that could be perceived to influence or have the potential to influence what is written in this work. The complete Disclosures of Potential Conflicts of Interest submitted by authors are always provided with the online version of the article. 
The Journal of Bone \& Joint Surgery · Jbjs.org Volume 95-A • Number $2 \cdot$ January 16,2013
Acetabular Components in Total Hip Arthroplasty

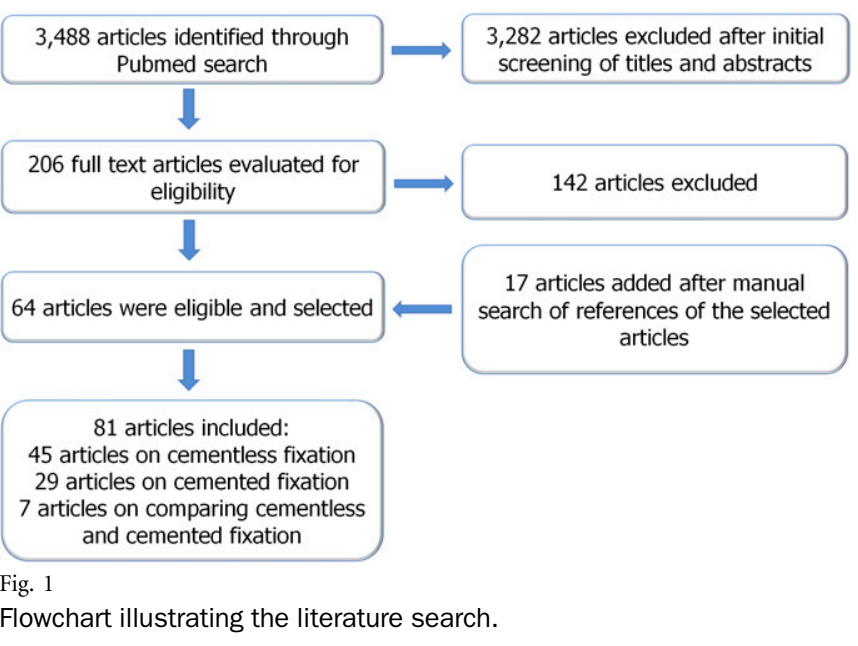

outcome measure in this systematic review. The revision rate and/or survivorship of the acetabular component for aseptic loosening represented a secondary end point.

\section{Data Extraction}

Two observers independently reviewed the titles and abstracts of the identified articles. If both observers agreed that a study did not meet the eligibility criteria, it was excluded. After screening of titles and abstracts, the full text of each of the remaining 206 articles was obtained and reviewed by the same two observers independently. Any disagreements were resolved by means of discussion with other members of the reviewing team. Sixty-four articles from the PubMed search were deemed eligible, and seventeen additional articles were added following manual searching of the reference lists of the former articles.

Data on the patient demographics, number of hips treated with total hip arthroplasty, underlying etiology leading to the total hip arthroplasty, duration of follow-up, number of hips or patients lost to follow-up, type of fixation of the acetabular component, the type of implant used, and survivorship or revision rate of the acetabular component were extracted and entered in a spreadsheet. If an article contained multiple subgroups of patients, only the data for the subgroup meeting the inclusion criteria were entered.

\section{Statistical Methods}

Two outcomes, the revision rate and survivorship, were compared across the studies. The number of arthroplasties and the total number with the outcome of interest were extracted from each study. Two types of statistical analyses were performed on the extracted data. The first involved meta-analysis of the combined data from the seven articles that directly compared cemented and cementless acetabular components. The meta-analysis was performed with use of Review Manager (version 5.1 [2011]; The Nordic Cochrane Centre, The Cochrane Collaboration, Copenhagen, Denmark). Because of the known variations among the studies and the resulting heterogeneity in the effect sizes (significant at $\mathrm{p}=0.005$ for survival and borderline at $\mathrm{p}=0.08$ for revision), a random-effects Mantel-Haenszel model was used.

The second statistical comparison involved study-level logistic regression on the pooled data across all eighty-one relevant studies. The regression was carried out with use of the "glm" function in the R software package (version 2.14.1 [2011]; R Development Core Team, Vienna, Austria). The logistic regression models included overdispersion, which was expected because of the high variation among the studies. Weighting on the basis of the number of total hip arthroplasties was performed in the logistic regression models. The regression was modeled as a function of $(n, N-n)$ with use of the quasibinomial family to account for the high variation in the pooled binary data among the studies. Three types of models were used: (1) a simple model that considered only the type of acetabular component fixation as a predictor and

\section{Outcome Measures}

The long-term survivorship and/or revision rate of the acetabular component for any reason at more than ten years postoperatively represented the primary 
The Journal of Bone \& Joint Surgery Jbjs.org Volume 95-A · Number 2 · January 16, 2013

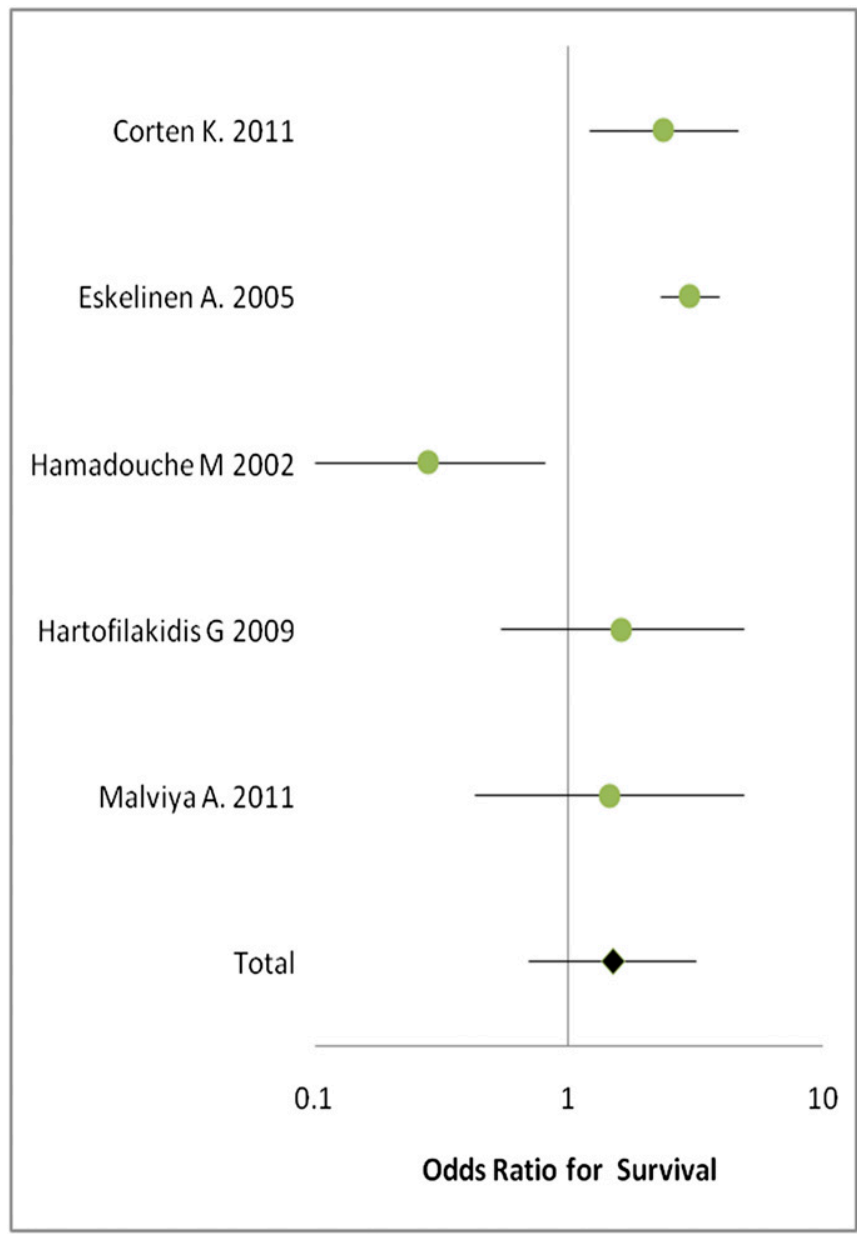

Fig. 2

Forest plot of the odds ratios for survival of a cemented acetabular component compared with a cementless one. The horizontal bars represent the confidence intervals, and the black diamond represents the cumulative odds ratio of the set of studies. The black diamond is to the right of the vertical line, indicating higher odds of survival of cemented components.

was most directly comparable with the meta-analysis results; (2) an ageadjusted model that considered the fixation type, whether the mean age was at least fifty-five years, and the interaction of fixation type with age; and (3) a full model that expanded on the age-adjusted model by adding the percentage of female patients, the preoperative diagnosis, the mean duration of follow-up, whether the study was prospective or retrospective, and the interaction of age with all of these terms. We did not adjust for the year of publication because many recent publications were actually updated reports of previous cohorts at longer follow-up, and adjusting for the year of publication would therefore not have helped to track the secular trends in practice over time.

\section{Source of Funding}

No external funding was received in support of this work.

\section{Results}

The studies included 26,576 primary total hip arthroplasties; 1 cemented acetabular fixation was used in 13,509 and not used in 13,067. The preoperative diagnoses (underlying disease leading to degeneration of the affected hip), demographics,
Acetabular Components in Total Hip Arthroplasty

types of implants used, and clinical results extracted from each of the included studies are summarized in the Appendix.

When data from all of the articles were pooled and logistic regression was performed with use of a quasibinomial family, the estimated odds ratio (OR) for survival of a cemented acetabular component compared with a cementless component was $1.57(95 \%$ confidence interval $[\mathrm{CI}], 1.15$ to $2.14 ; \mathrm{p}=$ 0.005). The estimated OR for revision of a cemented cup for any reason compared with revision of a cementless cup was 0.54 ( $95 \% \mathrm{CI}, 0.30$ to $0.98 ; \mathrm{p}=0.05)$. When the results were adjusted for age and other demographic variables, there was no significant difference between the rate of revision of cemented and cementless acetabular components $(\mathrm{p}=0.46)$. However, cemented components continued to have significantly greater survivorship than cementless cups; the estimated OR for survival for a cemented compared with a cementless acetabular component was $1.60(95 \% \mathrm{CI}, 1.32$ to $2.40 ; \mathrm{p}=0.02)$.

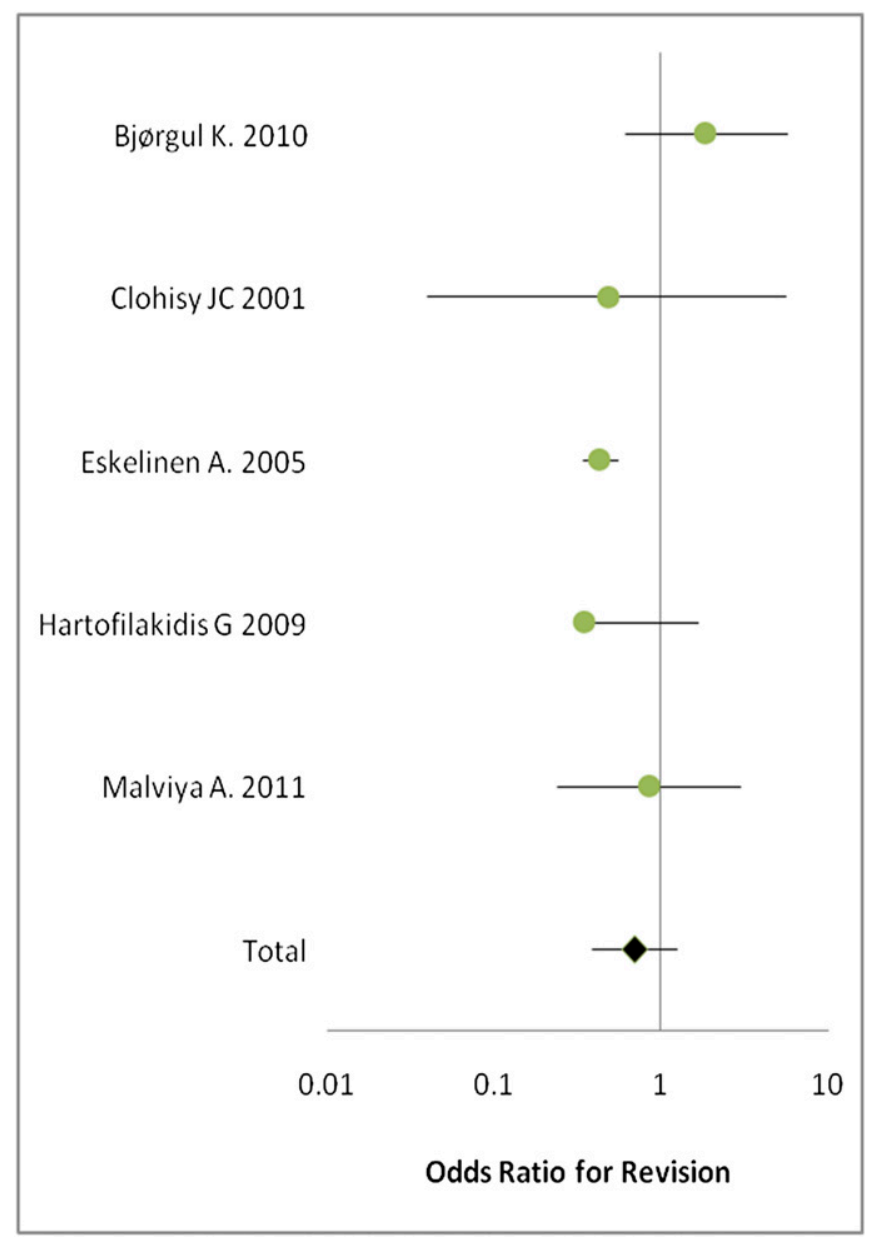

Fig. 3

Forest plot of the odds ratios for revision of a cemented acetabular component compared with a cementless one. The horizontal bars represent the confidence intervals, and the black diamond represents the cumulative odds ratio of the set of studies. The black diamond is to the left of the vertical line, indicating lower odds of revision of cemented components. 
The Journal of Bone \& Joint Surgery $\cdot$ Jbjs.org Volume 95-A - Number $2 \cdot$ January 16,2013
Acetabular Components in Total Hip Arthroplasty

performed in North America utilize an uncemented acetabular component. The usage of uncemented acetabular components during primary total hip arthroplasty is also on the rise in other countries. We are not aware of any literature that supports the superiority of an uncemented acetabular component over a cemented one ${ }^{18,23}$.

The current controversy regarding the optimal choice of acetabular fixation for total hip arthroplasty clearly originates from the various outcomes reported to date. The heterogeneities in the patient cohorts, materials and bearing surfaces utilized, and study designs each introduce a multitude of variables that skew the reported performance of cemented and cementless acetabular components. Thus, there is a clear necessity for an investigation performed across studies to determine if either acetabular fixation method (cemented or cementless) in total hip arthroplasty is linked to superior performance.

Previous systematic reviews ${ }^{18,23}$ pooled studies with shortterm and long-term outcomes, which may affect the conclusion drawn from these studies. The meta-analysis by Morshed et al. included twenty studies comparing total hip arthroplasty performed with and without cement, but some of these studies had a follow-up duration as short as one year ${ }^{18}$. Obviously, defining the survivorship of an implant on the basis of such a short-term follow-up could be misleading as inclusion of such results may partially mask survivorship differences in a meta-analysis. The systematic review by Yahiro et al. ${ }^{23}$ used similar follow-up criteria and therefore also included studies with short and intermediateterm follow-up. Both meta-analyses failed to show better survival of cementless cups compared with their cemented counterparts.

In some studies, failure of an implant was defined as revision for aseptic loosening ${ }^{23}$. However, in our view, a survival analysis with revision for any cause as the end point more adequately reflects the outcome of interest. Furthermore, the results of a survival analysis with revision as the end point are more predictable than those of an analysis based only on aseptic loosening, as the results of the latter analysis will depend on the definition of aseptic loosening that is selected ${ }^{24}$. Nonrevised hips are not necessarily successful, and many cup failures are symptomless for long periods, with loss of bone stock occurring in the absence of pain and disability ${ }^{25}$. Nevertheless, use of revision as an end point is a more objective and reliable approach for assessing the outcome of total hip arthroplasty. We also believe that a liner exchange in a cementless implant should be considered as a failure of the acetabular component, although the complexity and difficulty of a liner exchange procedure are often less than those of a cup revision for aseptic loosening. The authors of some studies have reported greater survival of cementless compared with cemented cups when the end point was revision for aseptic loosening but no difference in survival when the end point was revision for any reason (including liner exchange $)^{11}$. The present meta-analysis revealed no significant difference in survival between cementless and cemented acetabular components when the end point was revision for aseptic loosening. However, the survival of cemented acetabular components appeared to be better than that of cementless components when the end point included failure and revision for all causes. 
The present study has some limitations. A few Level-I studies $^{26-30}$ on this topic have been published, but the majority of the evaluated studies had a level of evidence of II or III, which reduced the strength of the evidence. Moreover, only seven of the included studies compared the long-term outcomes of cemented and cementless acetabular components, and the availability of matched data (to control for effects of important confounders that can influence survivorship of the acetabular component) was relatively limited. The remaining studies included reports on either cemented or cementless components but did not compare the outcome of these two types.

It is known that the outcome of total hip arthroplasty in general, and the survivorship of the acetabular component in particular, can be influenced by many variables other than the type of fixation, such as the polyethylene shelf life and method of sterilization, patient activity level, bone quality, and body mass index. Prior studies have not always adjusted for these important variables. Indeed, in the majority of the included studies, these variables were either not controlled for or not consistently reported. Consequently, given the large number of factors that can affect survival of an acetabular cup in total hip arthroplasty and the wide heterogeneity among these studies, we were not able to control for these variables in the metaanalysis with any degree of confidence.

Another limitation of the present study is related to the survival analyses in the included studies. Most of the included studies used the Kaplan-Meier method to estimate the probability of implant survival. Since the rate of death increases during long-term follow-up and death is a competing event in the Kaplan-Meier estimator, use of this method in the studies with a high rate of death (e.g., the studies by Callaghan et al. ${ }^{6}$ and Berry et al. ${ }^{5}$ ) is inappropriate and leads to either overestimation of the revision risk or underestimation of the survival probability $^{31}$. In an attempt to resolve this problem, Murray et al..$^{32}$ have suggested using a worst-case scenario analysis in which patients lost to follow-up are considered as failures. However, worst-case scenario analysis is not recommended for two reasons: it requires extrapolation of an unknown outcome, and it implies that censoring is not independent of the event mechanism, a situation in which the Kaplan-Meier method would not be valid ${ }^{31}$.

Another confounding factor is related to the observed improvement in survivorship over time of successive generations of cementless acetabular components. Some studies have indicated no difference in the survival rate between cemented and cementless cups in long-term follow-up when newergeneration cementless cups were used, whereas the oldergeneration cementless cups had less favorable results than cemented $\operatorname{cups}^{11,18}$. It is certain that earlier designs of cementless acetabular components were responsible for substantial underperformance of these components. For example, threaded acetabular components with a smooth surface treatment had the worst survival rate in the long-term studies ${ }^{8,14}$. However, inclusion of these studies in the present meta-analysis will not impact the results and comparisons substantially because many studies involving early cemented acetabular components with crude cementing techniques and poor performance were also included $^{33,34}$.

Despite the aforementioned limitations, the findings of this study are important because they highlight the lack of sufficient evidence for superior survivorship of cementless acetabular components at a minimum of ten years of followup. Ongoing critical review to twenty years and beyond is required because the advantage of one fixation method over another may become apparent at long-term follow-up. Future studies can also take into account the role that alternative bearing surfaces may play in enhancing survivorship of cementless acetabular components.

\section{Appendix}

eA Tables summarizing patient demographics, implant types, eA and clinical results in each of the included studies are available with the online version of this article as a data supplement at jbjs.org.

Nader Toossi, MD

Bahar Adeli, BA

Mitchell Maltenfort, $\mathrm{PhD}$

Javad Parvizi, MD, FRCS

Rothman Institute of Orthopedics,

Thomas Jefferson University,

925 Chestnut Street,

Philadelphia, PA 19107.

E-mail address for J. Parvizi: parvj@aol.com

Andrew J. Timperley, DPhil, FRCS

Exeter Hip Unit, Princess Elizabeth Orthopaedic Centre,

Royal Devon \& Exeter Hospital,

Barrack Road,

Exeter EX2 5DW, United Kingdom

Fares S. Haddad, FRCS

LAT (ST3) Trauma and Orthopaedics,

University College London Hospital,

235 Euston Road,

London NW1 2BU, United Kingdom

\section{References}

1. Charnley J. The long-term results of low-friction arthroplasty of the hip performed as a primary intervention. J Bone Joint Surg Br. 1972 Feb;54(1):61-76.

2. Veitch SW, Whitehouse SL, Howell JR, Hubble MJ, Gie GA, Timperley AJ. The concentric all-polyethylene Exeter acetabular component in primary total hip replacement. J Bone Joint Surg Br. 2010 Oct;92(10):1351-5.
3. Devitt A, O'Sullivan T, Quinlan W. 16- to 25-year follow-up study of cemented arthroplasty of the hip in patients aged 50 years or younger. J Arthroplasty. 1997 Aug;12(5):479-89.

4. Klapach AS, Callaghan JJ, Goetz DD, Olejniczak JP, Johnston RC. Charnley total hip arthroplasty with use of improved cementing techniques: a minimum 
The Journal of Bone \& Joint Surgery $\cdot$ Jbjs.org Volume 95-A • Number $2 \cdot$ January 16,2013
Acetabular Components in TOTal Hip Arthroplasty Charnley cups. J Orthop Traumatol. 2010 Mar;11(1):37-45. Epub 2010 Mar 3. 29. Stilling $M$, Rahbek $O$, Søballe $K$. Inferior survival of hydroxyapatite versus titanium-coated cups at 15 years. Clin Orthop Relat Res. 2009 Nov;467(11): 2872-9. Epub 2009 Mar 28.

30. Clohisy JC, Harris WH. Matched-pair analysis of cemented and cementless acetabular reconstruction in primary total hip arthroplasty. J Arthroplasty. 2001 Sep;16(6):697-705.

31. Biau DJ, Latouche A, Porcher R. Competing events influence estimated survival probability: when is Kaplan-Meier analysis appropriate? Clin Orthop Relat Res. 2007 Sep;462:229-33.

32. Murray DW, Britton AR, Bulstrode CJ. Loss to follow-up matters. J Bone Joint Surg Br. 1997 Mar;79(2):254-7.

33. Chmell MJ, Scott RD, Thomas WH, Sledge CB. Total hip arthroplasty with cement for juvenile rheumatoid arthritis. Results at a minimum of ten years in patients less than thirty years old. J Bone Joint Surg Am. 1997 Jan;79(1):44-52.

34. Sochart $\mathrm{DH}$, Porter ML. Long-term results of total hip replacement in young patients who had ankylosing spondylitis. Eighteen to thirty-year results with survivorship analysis. J Bone Joint Surg Am. 1997 Aug;79(8):1181-9.

35. Alho A, Lepistö J, Ylinen P, Paavilainen T. Cemented Lubinus and Furlog total hip endoprosthesis: a 12-year follow-up study of 175 hips comparing the cementing technique. Arch Orthop Trauma Surg. 2000;120(5-6):276-80.

36. Brady LP, McCutchen JW. A ten-year follow-up study of 170 Charnley total hip arthroplasties. Clin Orthop Relat Res. 1986 Oct;(211):51-4.

37. Brick GW, Poss R. Long-term follow-up of cemented total hip replacement for osteoarthritis. Rheum Dis Clin North Am. 1988 Dec;14(3):565-77.

38. Della Valle CJ, Kaplan K, Jazrawi A, Ahmed S, Jaffe WL. Primary total hip arthroplasty with a flanged, cemented all-polyethylene acetabular component: evaluation at a minimum of 20 years. J Arthroplasty. 2004 Jan;19(1):23-6.

39. Dorr LD, Kane TJ 3rd, Conaty JP. Long-term results of cemented total hip arthroplasty in patients 45 years old or younger. A 16-year follow-up study. J Arthroplasty. 1994 Oct;9(5):453-6.

40. Garellick G, Herberts $P$, Strömberg $C$, Malchau H. Long-term results of Charnley arthroplasty. A 12-16-year follow-up study. J Arthroplasty. 1994 Aug;9(4):333-40.

41. Goto $K$, Akiyama $H$, Kawanabe $K$, So K, Morimoto $T$, Nakamura T. Long-term results of cemented total hip arthroplasty for dysplasia, with structural autograft fixed with poly-L-lactic acid screws. J Arthroplasty. 2009 Dec;24(8):1146-51. Epub 2009 Jun 24.

42. Keener JD, Callaghan JJ, Goetz DD, Pederson DR, Sullivan PM, Johnston RC. Twenty-five-year results after Charnley total hip arthroplasty in patients less than fifty years old: a concise follow-up of a previous report. J Bone Joint Surg Am. 2003 Jun;85-A(6):1066-72.

43. Kobayashi S, Eftekhar NS, Terayama K, Joshi RP. Comparative study of total hip arthroplasty between younger and older patients. Clin Orthop Relat Res. 1997 Jun;(339):140-51.

44. Lehtimäki MY, Lehto $M U$, Kautiainen $H$, Savolainen $H A$, Hämäläinen MM. Survivorship of the Charnley total hip arthroplasty in juvenile chronic arthritis. A follow-up of 186 cases for 22 years. J Bone Joint Surg Br. 1997 Sep;79(5):792-5.

45. Levy BA, Berry DJ, Pagnano MW. Long-term survivorship of cemented allpolyethylene acetabular components in patients $>75$ years of age. J Arthroplasty. 2000 Jun;15(4):461-7.

46. McCoy TH, Salvati EA, Ranawat CS, Wilson PD Jr. A fifteen-year follow-up study of one hundred Charnley low-friction arthroplasties. Orthop Clin North Am. 1988 Jul;19(3):467-76.

47. Mulroy WF, Estok DM, Harris WH. Total hip arthroplasty with use of so-called second-generation cementing techniques. A fifteen-year-average follow-up study. J Bone Joint Surg Am. 1995 Dec;77(12):1845-52.

48. Nich C, Courpied JP, Kerboull M, Postel M, Hamadouche M. Charnley-Kerboull total hip arthroplasty for osteonecrosis of the femoral head a minimal 10-year followup study. J Arthroplasty. 2006 Jun;21(4):533-40.

49. Ortiguera CJ, Pulliam IT, Cabanela ME. Total hip arthroplasty for osteonecrosis: matched-pair analysis of 188 hips with long-term follow-up. J Arthroplasty. 1999 Jan;14(1):21-8.

50. Ritter MA, Campbell ED. Long-term comparison of the Charnley, Muller, and Trapezoidal-28 total hip prostheses. A survival analysis. J Arthroplasty. 1987;2(4):299-308.

51. Sochart DH, Hardinge K. Comparison of the Wrightington FC hip with the Charnley low-friction arthroplasty. 10- to 15-year results and survival analysis. J Bone Joint Surg Br. 1998 Jul;80(4):577-84.

52. Somford MP, Bolder SB, Gardeniers JW, Slooff TJ, Schreurs BW. Favorable survival of acetabular reconstruction with bone impaction grafting in dysplastic hips. Clin Orthop Relat Res. 2008 Feb;466(2):359-65. Epub 2008 Jan 10.

53. Unger AS, Inglis AE, Ranawat CS, Johanson NA. Total hip arthroplasty in rheumatoid arthritis. A long-term follow-up study. J Arthroplasty. 1987;2(3):191-7. 54. Urban JA, Garvin KL, Boese CK, Bryson L, Pedersen DR, Callaghan JJ, Miller RK. Ceramic-on-polyethylene bearing surfaces in total hip arthroplasty. Seventeen to twenty-one-year results. J Bone Joint Surg Am. 2001 Nov;83-A(11):1688-94. 
The Journal of Bone \& Joint Surgery $\cdot$ Jbjs.org Volume 95-A • Number $2 \cdot$ January 16,2013
Acetabular Components in Total Hip Arthroplasty
55. Welten ML, Schreurs BW, Buma P, Verdonschot N, Slooff TJ. Acetabular reconstruction with impacted morcellized cancellous bone autograft and cemented primary total hip arthroplasty: a 10- to 17-year follow-up study. J Arthroplasty. 2000 Oct;15(7):819-24.

56. Belmont PJ Jr, Powers CC, Beykirch SE, Hopper RH Jr, Engh CA Jr, Engh CA. Results of the anatomic medullary locking total hip arthroplasty at a minimum of twenty years. A concise follow-up of previous reports. J Bone Joint Surg Am. 2008 Jul;90(7):1524-30.

57. Berli BJ, Ping G, Dick W, Morscher EW. Nonmodular flexible press-fit cup in primary total hip arthroplasty: 15-year followup. Clin Orthop Relat Res. 2007 Aug;461:114-21.

58. Bidar R, Kouyoumdjian $P$, Munini E, Asencio G. Long-term results of the ABG-1 hydroxyapatite coated total hip arthroplasty: analysis of 111 cases with a minimum follow-up of 10 years. Orthop Traumatol Surg Res. 2009 Dec;95(8):579-87.

59. Bojescul JA, Xenos JS, Callaghan JJ, Savory CG. Results of porous-coated anatomic total hip arthroplasty without cement at fifteen years: a concise follow-up of a previous report. J Bone Joint Surg Am. 2003 Jun;85-A(6):1079-83.

60. Bourne RB, Rorabeck $\mathrm{CH}$, Patterson JJ, Guerin J. Tapered titanium cementless total hip replacements: a 10- to 13-year followup study. Clin Orthop Relat Res. 2001 Dec;(393):112-20.

61. Civinini R, D'Arienzo M, Innocenti M 2nd. A ten-year follow-up of the Reflection cementless acetabular component. J Bone Joint Surg Br. 2008 May;90(5):570-3. 62. Della Valle CJ, Berger RA, Shott S, Rosenberg AG, Jacobs JJ, Quigley L, Galante JO. Primary total hip arthroplasty with a porous-coated acetabular component. A concise follow-up of a previous report. J Bone Joint Surg Am. 2004 Jun;86-A(6):1217-22. 63. Duffy GP, Berry DJ, Rowland C, Cabanela ME. Primary uncemented total hip arthroplasty in patients $<40$ years old: 10 - to 14-year results using first-generation proximally porous-coated implants. J Arthroplasty. 2001 Dec;16(8 Suppl 1):140-4. 64. Duffy GP, Prpa B, Rowland CM, Berry DJ. Primary uncemented Harris-Galante acetabular components in patients 50 years old or younger: results at 10 to 12 years. Clin Orthop Relat Res. 2004 Oct;(427):157-61.

65. Gabbar OA, Rajan RA, Londhe S, Hyde ID. Ten- to twelve-year follow-up of the furlong hydroxyapatite-coated femoral stem and threaded acetabular cup in patients younger than 65 years. J Arthroplasty. 2008 Apr;23(3):413-7.

66. Gaffey JL, Callaghan JJ, Pedersen DR, Goetz DD, Sullivan PM, Johnston RC. Cementless acetabular fixation at fifteen years. A comparison with the same surgeon's results following acetabular fixation with cement. J Bone Joint Surg Am. 2004 Feb;86-A(2):257-61.

67. Götze C, Tschugunow A, Götze HG, Böttner F, Pötzl W, Gosheger G. Long-term results of the metal-cancellous cementless Lübeck total hip arthroplasty: a critical review at 12.8 years. Arch Orthop Trauma Surg. 2006 Jan;126(1):28-35. Epub 2005 Nov 10.

68. Grobler GP, Learmonth ID, Bernstein BP, Dower BJ. Ten-year results of a pressfit, porous-coated acetabular component. J Bone Joint Surg Br. 2005 Jun;87(6):786-9. 69. Grübl A, Chiari C, Giurea A, Gruber M, Kaider A, Marker M, Zehetgruber H, Gottsauner-Wolf F. Cementless total hip arthroplasty with the rectangular titanium Zweymuller stem. A concise follow-up, at a minimum of fifteen years, of a previous report. J Bone Joint Surg Am. 2006 Oct;88(10):2210-5.

70. Hallan G, Dybvik E, Furnes $O$, Havelin LI. Metal-backed acetabular components with conventional polyethylene: a review of 9113 primary components with a followup of 20 years. J Bone Joint Surg Br. 2010 Feb;92(2):196-201.

71. Ihle M, Mai S, Pfluger $D$, Siebert $W$. The results of the titanium-coated RM acetabular component at 20 years: a long-term follow-up of an uncemented primary total hip replacement. J Bone Joint Surg Br. 2008 Oct;90(10):1284-90.

72. Kawamura $\mathrm{H}$, Dunbar MJ, Murray $\mathrm{P}$, Bourne RB, Rorabeck $\mathrm{CH}$. The porous coated anatomic total hip replacement. A ten to fourteen-year follow-up study of a cementless total hip arthroplasty. J Bone Joint Surg Am. 2001 Sep;83-A(9):1333-8. 73. Kim YG, Kim SY, Park BC, Kim PT, Ihn JC, Kim ID. Uncemented Harris-Galante total hip arthroplasty in patients with osteonecrosis of the femoral head. A 10-16year follow-up study. Acta Orthop. 2005 Feb;76(1):42-8.

74. Kim YH, Choi Y, Kim JS. Cementless total hip arthroplasty with ceramic-onceramic bearing in patients younger than 45 years with femoral-head osteonecrosis. Int Orthop. 2010 Dec;34(8):1123-7. Epub 2009 Sep 26.

75. Kim YH, Kim JS, Cho SH. Primary total hip arthroplasty with the AML total hip prosthesis. Clin Orthop Relat Res. 1999 Mar;(360):147-58.
76. Kim YH. Long-term results of the cementless porous-coated anatomic total hip prosthesis. J Bone Joint Surg Br. 2005 May;87(5):623-7.

77. Kim YH, Kim JS, Yoon SH. Long-term survivorship of the Charnley Elite Plus femoral component in young patients. J Bone Joint Surg Br. 2007 Apr;89(4):449-54 78. Lee YK, Ha YC, Yoo JJ, Koo KH, Yoon KS, Kim HJ. Alumina-on-alumina total hip arthroplasty: a concise follow-up, at a minimum of ten years, of a previous report. J Bone Joint Surg Am. 2010 Jul 21;92(8):1715-9.

79. Little BS, Wixson RL, Stulberg SD. Total hip arthroplasty with the porous-coated anatomic hip prosthesis: results at 11 to 18 years. J Arthroplasty. 2006 Apr;21(3):338-43.

80. Lybäck CC, Lybäck CO, Kyrö A, Kautiainen HJ, Belt EA. A long-term follow-up of 60 Lord total hip arthroplasties in rheumatic disease: a mean follow-up of 14 years. Int Orthop. 2006 Oct;30(5):391-4. Epub 2006 May 12.

81. Malchau $H$, Herberts $P$, Wang $Y X$, Kärrholm J, Romanus B. Long-term clinical and radiological results of the Lord total hip prosthesis. A prospective study. J Bone Joint Surg Br. 1996 Nov;78(6):884-91.

82. McLaughlin JR, Lee KR. Cementless total hip replacement using secondgeneration components: a 12- to 16-year follow-up. J Bone Joint Surg Br. 2010 Dec;92(12):1636-41.

83. Müller LA, Wenger N, Schramm M, Hohmann D, Forst R, Carl HD. 17-year followup of the rough-blasted threaded Weill cup in uncemented total hip arthroplasty. Arch Orthop Trauma Surg. 2011 Apr;131(4):557-61. Epub 2010 Dec 15.

84. Parvizi J, Sullivan T, Duffy G, Cabanela ME. Fifteen-year clinical survivorship of Harris-Galante total hip arthroplasty. J Arthroplasty. 2004 Sep;19(6):672-7.

85. Petsatodis GE, Papadopoulos PP, Papavasiliou KA, Hatzokos IG, Agathangelidis FG, Christodoulou AG. Primary cementless total hip arthroplasty with an alumina ceramic-on-ceramic bearing: results after a minimum of twenty years of follow-up. J Bone Joint Surg Am. 2010 Mar;92(3):639-44.

86. Pospischill M, Knahr K. Cementless total hip arthroplasty using a threaded cup and a rectangular tapered stem. Follow-up for ten to 17 years. J Bone Joint Surg Br. 2005 Sep;87(9):1210-5.

87. Raj D, Jaiswal PK, Sharma BL, Fergusson CM. Long term results of the Corin C-Fit uncemented total hip arthroplasty in young patients. Arch Orthop Trauma Surg. 2008 Dec;128(12):1391-5. Epub 2008 Jan 5.

88. Reigstad $O$, Siewers $P$, Røkkum M, Espehaug B. Excellent long-term survival of an uncemented press-fit stem and screw cup in young patients: follow-up of 75 hips for 15-18 years. Acta Orthop. 2008 Apr;79(2):194-202.

89. Reikerås $O$, Gunderson RB. Long-term results of $H A$ coated threaded versus $H A$ coated hemispheric press fit cups: 287 hips followed for 11 to 16 years. Arch Orthop Trauma Surg. 2006 Oct;126(8):503-8. Epub 2006 Jun 24.

90. Suckel A, Geiger F, Kinzl L, Wulker N, Garbrecht M. Long-term results for the uncemented Zweymuller/Alloclassic hip endoprosthesis. A 15-year minimum followup of 320 hip operations. J Arthroplasty. 2009 Sep;24(6):846-53. Epub 2008 Sep 11.

91. Trebse R, Milosev I, Kovac S, Mikek M, Pisot V. Poor results from the isoelastic total hip replacement: 14-17-year follow-up of 149 cementless prostheses. Acta Orthop. 2005 Apr;76(2):169-76.

92. Utting MR, Raghuvanshi M, Amirfeyz R, Blom AW, Learmonth ID, Bannister GC. The Harris-Galante porous-coated, hemispherical, polyethylene-lined acetabular component in patients under 50 years of age: a 12- to 16-year review. J Bone Joint Surg Br. 2008 Nov;90(11):1422-7.

93. Zweymüller KA, Steindl M, Schwarzinger U. Good stability and minimal osteolysis with a biconical threaded cup at 10 years. Clin Orthop Relat Res. 2007 Oct;463:128-37.

94. Hamadouche M, Boutin P, Daussange J, Bolander ME, Sedel L. Alumina-onalumina total hip arthroplasty: a minimum 18.5-year follow-up study. J Bone Joint Surg Am. 2002 Jan;84-A(1):69-77.

95. Hartofilakidis G, Georgiades G, Babis GC. A comparison of the outcome of cemented all-polyethylene and cementless metal-backed acetabular sockets in primary total hip arthroplasty. J Arthroplasty. 2009 Feb;24(2):217-25. Epub 2008 Mar 28.

96. Malviya A, Walker LC, Avery P, Osborne S, Weir DJ, Foster HE, Deehan DJ. The long-term outcome of hip replacement in adults with juvenile idiopathic arthritis: the influence of steroids and methotrexate. J Bone Joint Surg Br. 2011 Apr;93(4):443-8. 